\title{
On the Nature of Immersion During Study Abroad: Some Participant Perspectives
}

\author{
Sharon wilkinson
}

West Virginia University

\section{Introduction}

The fastest way to become fluent in a language is to live in the host country with a family that has limited English skills and in an area that attracts few English-speaking tourists. The French language program at Valcourt was established to provide this ideal environment for intermediate French students who want to make a quantum leap in their oral language proficiency. (Valcourt program brochure, 1994) ${ }^{1}$

The view of study abroad expressed in the opening lines of Collegiate University's Valcourt program recruitment brochure reflects a commonly held perspective on the prowess of an immersion environment to bring about dramatic learning gains. Such beliefs are further underscored by research documenting increases in language skills, as measured by pre- and post-test scores as well as by comparisons with students who have not studied abroad (e.g., Brecht, Davidson, \& Ginsberg, 1993; Carlson, Burn, Useem, \& Yachimowicz, 1990; Freed, 1990, 1995b; Lafford, 1995; Milleret, 1991). Studies such as these have provided valuable insight into some common results of time spent overseas. But what if we were to focus on the nature of the immersion context rather than on its products? What happens during a sojourn in a different cultural and linguistic environment? What kinds of contacts do students have within such a context? And perhaps most importantly, how do the participants 
themselves perceive these encounters, particularly in view of their expectations for immersion?

An initial attempt has been made in several studies to classify the types of target-language contacts sought by participants overseas (Brecht \& Robinson, 1993; Kaplan, 1989; Freed, 1990). However, as Freed (1995a) notes, "there are numerous variations of the study abroad experience and it is rarely, if ever, possible to describe with precision the quality and extent of social contact and linguistic interaction" (5). Perhaps this vast diversity accounts in part for the relative dearth of research-based descriptions of the immersion context and students' behaviors within that environment. Indeed, Goodwin and Nacht (1988) in their overview of the various types of education abroad programs liken studying in a foreign country to learning to swim in unknown waters, differentiating program models according to the method of aquatic instruction ("plunging in midstream," "swimming in the eddies," and so on). It is certainly not difficult to imagine how the waters of the host culture "river" could take on a multitude of different appearances depending on how one was introduced to swimming in them. In other words, a variety of program factors, such as the length of stay, the role of program administrators, the types of housing available, the nature of any orientation sessions and overseas support systems, the role of academics, and so forth-particularly as potential mediators of the participants' contacts with their surroundings-can play an influential role in shaping immersion experiences (cf. De Ley, 1975). Accounting for such numerous characteristics creates a challenge for the researcher attempting to understand and depict the study-abroad environment.

In addition to a wide variety of program designs, one must also consider factors related to the diversity of host cultures and individual participants. It stands to reason that an American student of French, for example, will experience immersion differently depending on whether she studies in Quebec, Belgium, or Senegal, since the potential for acclimation problems varies according to the nature of anticipated and unanticipated differences between home and host cultures. Similarly, two individuals participating in the same program in the same country will likely encounter their surroundings in two unique ways as well, given the multitude of personal factors that come into play. Brecht, Davidson, and Ginsberg (1993), in their large-scale study of American students on 
semester and academic-year programs in Russia, isolated several predeparture variables that were statistically significant in predicting language gain during study abroad: gender (men seem to be more likely than women to improve listening and speaking skills), age (younger students tend to make more progress in listening), knowledge of other foreign languages (the more foreign languages one knows, the greater the gain in Russian), grammar and reading knowledge in Russian (a higher score on a Russian grammar and reading exam prior to departure predicts greater gain while overseas), and language learning aptitude (a higher score on the MLAT3 and MLAT4 exams predicts improvement of listening and reading skills).

Several of these findings are corroborated in other studies as well. Freed (1990) indicated that proficiency level correlated positively with amount of both productive and receptive language contact in a French summer abroad program, a finding which paralleled Kaplan's (1989) survey results of the amount and type of language use by summer immersion students in France. Like language level, the issue of gender has also been given attention in several other studies (Brecht \& Robinson, 1993; Kline, 1993; Polanyi, 1995; Twombly, 1995), each suggesting that the immersion experiences of men and women are qualitatively different with women at a disadvantage in making and maintaining contact with native speakers. Additionally, Laubscher (1994) notes that since contact with one native speaker will often lead to further opportunities to establish ties with other host nationals, an individual's success at making one acquaintance can impact his out-of-class experiences tremendously. Not surprisingly, personality differences also seem to play an important role in the quantity and quality of students' interactions with native speakers, as well as in their perceptions and interpretations of those encounters (DeKeyser, 1991; Pellegrino, 1997).

Given the sheer number of possible combinations of program, hostculture, and participant factors, any attempt to establish a singular, generalized understanding of the overseas context seems hardly advisable. The potential diversity, particularly at the level of the individual, certainly argues strongly for the value of a case-study approach in seeking answers to questions about the study abroad environment. Thus, the pages that follow explore the nature of the immersion context through the eyes of two American undergraduate women who participated in 
Collegiate University's 1994 summer study abroad program in Valcourt, France. Their expectations and experiences, told in their own words, are further echoed in the stories of other overseas-program participants recounted in a small but growing number of qualitative investigations of study abroad (e.g., Kline, 1993; Pellegrino, 1997; Siegal, 1995). Together, these student perspectives underscore the immense complexity and intense individuality of the immersion experience that are often overlooked in statistical representations of the overseas context.

\section{B ackgrounds: Participants, program, and research project}

Sipping a large soft drink at the McDonald's adjacent to the Collegiate University (CU) campus, Molise Dom recounted vivid childhood memories from far away places. "We lived in Cambodia until I was about six. Well, lived," she qualified, "if you could call it that. More like survived day to day." She told of her family's escape on foot to Thailand and of their tension-filled border crossing, which hinged on her father's native-like command of Vietnamese to convince the Cambodian guards to let them pass as "foreigners." After almost two years in Thai and Philippine refugee camps, the Dom family came to settle in the United States. Molise recalled the process of learning English, "I didn't know even one word! ... [But] I had some very patient teachers [in elementary school]." She laughed, "Sometimes now in French class, I'm like, 'Here I go again!' "

At Collegiate, an emphasis on Francophone texts and films in her French 3 class revealed a cultural side of the French language with which Molise could identify: the characters' struggles between indigenous roots and French rule paralleled her own tug-of-war between her Cambodian heritage and American surroundings. A summer abroad experience in France thus represented an opportunity for Molise to immerse herself in French language and culture, in much the same way she had come to know American English and cultural norms.

Ashley Crawford, too, was no stranger to other cultures. Her parents, having never had the opportunity to travel when they were younger, had decided to see as much of the world as possible and to take Ashley and her sister with them. "When I was three, we went to Mexico; when I was 
six, we did England and France...." Her list of international travel destinations included nine countries or regions on three continents. Over the years, the Dominican Republic had become the Crawfords' favorite locale for beach vacations, and Ashley had made friends on the island. "It sure changes your perspective to meet people," she observed. "The Dominican Republic's a very poor country, and you might never see that if you're just a tourist at a fancy resort." Ashley had also learned to appreciate the "laidback lifestyle" of the people and their love for celebrations. She imagined how stifling it would be for her Caribbean friends to come to Collegiate, where "there's no place to dance all night long."

Having studied French in high school and at CU, Ashley wanted to experience France as "more than a tourist." As a member of the University fencing team, however, she did not feel that she could afford a semester overseas. The Valcourt summer program offered a workable alternative. Hoping to maximize her chances of becoming "more fluent" in French (i.e., "not have to stop and think about grammar rules and vocabulary"), Ashley opted for the eight-week version of the program instead of four weeks, as most of the other participants had chosen: "I figure it'll take me four weeks just to get used to speaking French, and I really want to improve."

The Valcourt program itself was founded in 1990 with the aim of supplementing existing semester and academic-year programs available through Collegiate University and providing an opportunity for students with as little as two semesters of language instruction to study in France. Administratively, the program was a joint effort between Collegiate and the Institut International d'Etudes Linguistiques (IIEL), a language school for foreign students in Valcourt. Through a faculty adviser, CU took responsibility for recruiting participants, helping them fill out the necessary application forms, and escorting them to Valcourt. The IIEL then arranged student housing, provided all formal instruction, and offered optional day excursions on the weekends for an additional fee. There was no representative of Collegiate University present in Valcourt during the students' stay. Similarly, no pre-departure orientation sessions were offered beyond three informational meetings for the purpose of arranging travel logistics and IIEL enrollment.

In Valcourt, two types of living arrangements were available to participants: room and partial board (breakfasts and dinners) with a French 
host family or the substantially less expensive single room in a university dormitory. Both Molise and Ashley chose to request a host family with the aim of increasing their chances for interaction with French people. Housing fees were set uniformly by the IIEL, but all financial transactions were handled directly between student and host, a situation which Ashley found "awkward, to say the least," since "it's like paying someone to be your friend."

As mentioned above, participants were also given a choice on the length of their stay. Four weeks abroad in June earned them four credit hours of French at Collegiate; extending their stay for an additional fourweek session in July doubled the transferred credits to eight. These credits were used to replace the next appropriate French class in the student's course of study at Collegiate, regardless of placement level at the IIEL.

Upon arrival in Valcourt, the students spent Monday morning taking a battery of placement tests, both oral and written. Both Ashley and Molise placed into the same intermediate-level class, and, like all IIEL students, were scheduled for 25 hours of French instruction per week.

In sum, Ashley and Molise had much in common as they began their immersion experience. For both, crossing cultural boundaries was already a way of life, and their choice to study overseas seemed a natural extension of it. They arrived in Valcourt with a similar linguistic foundation in French. Both had chosen the host-family housing option and were enthusiastic about the potential opportunities for linguistic and cultural learning afforded by in-country immersion. Both expressed high motivation to seek out opportunities to use their French with native speakers.

Molise and Ashley had also agreed, along with five other participants from Collegiate, to serve as informants in a qualitative research project which sought to understand-from their point of view-the transition they were making from language learning in an American classroom to language use in Valcourt and back again. Over an eight-month span of time, the group participated in ethnographic interviews (Spradley, 1979) and observations (Spradley, 1980), tape-recorded conversations in French with each other and with native speakers, as well as other opportunities for documenting their experiences overseas, such as time-place maps (Brecht \& Robinson, 1993), mental maps of Valcourt, and photo journals. ${ }^{2}$ The resulting data show, among other things, how truly unique each participant's perspective can be, even when backgrounds seem similar. 


\section{Expectations and Experiences}

Immersion in Valcourt theoretically offered similar opportunities for linguistic and cultural contact as those documented in other studies, e.g., meals with host families, newspapers, television, movies, shopping, restaurants, errands to the post office, bank, train station, etc. (Kaplan, 1989; Freed, 1990). In this section, data on these encounters are grouped in two main categories according to informant's primary expectations for immersion: (1) expectations for immersion in the host family, and (2) expectations for immersion in the host community.

\section{A member of the family}

"I hope I get a good family" was the most consistently expressed concern across all seven participants in the Valcourt program during predeparture interviews. "Good" was generally defined as "a family like mine," to which one informant added, "if we had an exchange student from France staying with us, we'd show them around everywhere!" The extent to which this expectation was met varied considerably.

Molise considered herself "lucky." Her hosts treated her "like a real member of the family," and she reacted in kind, spending her free time playing games with her "little sister" and helping her host parents tend their garden on a rented plot in the countryside surrounding Valcourt. At the end of her stay, her family invited her to stay two more months so that she could vacation with them for three weeks in August. Since Molise could not change her summer plans on such short notice, they suggested that she return to France the following August to take a camping trip with them, an offer which she accepted.

Ashley's host family, on the other hand, did not conform to her expectations even from the very beginning:

When we got there at the train station,... I was really excited to see all the people and to meet my family and everything, and everybody slowly came and picked up their child-not their child, but whatever-their student, and then I was the only one standing there.... So then the IIEL guy dropped me off at the house, and I remember it was raining, and that like added to the ambience of the whole thing.... 
And they dropped me off, and I saw this guy standing there with his dog.... He didn't bother to tell me anything about himself; he just walked me up to the apartment and up to the room and everything. And ubm, oh, he just pointed out, he said, "This is your room.".. It made me really uncomfortable-you know, I was sitting there with this guy who wouldn't talk to me very much.... Then finally, though, I had been there maybe three and a half hours, and Chantal ther host mother\} comes like flying in-like, walking, like she walked really hard and really fast, and you could always hear her coming, like stomping down the hallway. And she ran in and she goes, "Oh. Bonjour."... And then just left. You know, like stormed out.

It became particularly clear to Ashley that her hopes of being welcomed as another "child" in her French family would not be realized after another incident during the first week of her stay. Wanting to be "extra polite," Ashley asked her host's permission to spend the evening out with friends from Collegiate. She reported Chantal's reply: "I don't care if you don't come back for five days!" In comparison with the pre-departure image she had of the "carefully chosen" French family advertised in the Valcourt program literature, Ashley's actual experience was disappointing and frustrating to her, particularly since it represented, from her perspective, the closing of her most promising window on French society.

Even if most hosts are not as detached as Chantal apparently was, it is not uncommon for home stays to fall short of participants' expectations for immersion, as the following quote from Kline's (1993) ethnographic study of a junior-year abroad program in France further illustrates:

My family was there when we got to Marcillac, you know: "You must be Martha." They pretty much left me at home at first, but they said I could come up to see them whenever I wanted to. I remember being scared ... I mean, I just didn't want to be there... It was a little stiff with my host family at first. You know, you say, "This is my state, Massachusetts," kinda dorky. I remember thinking, "This is all I can tell you in French." And they'd ask the same questions every day, like "What did you do today?" I remember hoping it wasn't going to be like this all year long.... (At the end of the year) saying goodbye ... I was sad, but it just didn't click. I would go back and visit, but I'm glad I don't have to live there again. $(38,40)$ 
De Ley (1975) summarizes the problem succinctly:

The traditional famille d'accueil rationale that students learn French more effectively if dispersed far from their fellow Americans, in different parts of the site city, alone in their "French families"... also means students live in enforced, more or less intimate contact with a subculture ruled by its own unfamiliar economy and mores. From the point of view of stranger anxiety, the famille d'accueil may not be a situation in which the student feels "at home," but rather a particularly complex example of the difficulties of the foreign environment. (842)

Naturally, home stays are not the only possibility a study abroad student has for encountering host nationals. However, for most of the students on the Valcourt program, the most frequent and consistent contacts did seem to be in the home. Thus for Ashley, French immersion seemed limited, despite living in France:

The opportunities I had (to use my French)-that was one thing that I was sort of disappointed with 'cause I really didn't get a chance to talk that much because of the situation with my bost family. And then I talked in French in class, but then I didn't really talk. And ubm I didn't know any French people.... Going to a place like the IIEL where there aren't French students, you don't get the chance to make any French friends. I mean, I don't know anyone in France, you know, from the whole experience like to write to or anything.

Molise, in contrast, did correspond with her host family after her return to the United States, an observation that was considered newsworthy among the Collegiate cohort and that signified for them that she had somehow succeeded at study abroad in a way that had not materialized for them.

In addition to hopes and expectations for a home stay, Ashley and Molise also looked forward to being immersed in French language and culture in the streets of Valcourt and to practicing their language skills in real-life settings. These aspirations, too, were realized to varying degrees of personal satisfaction, as the following section reveals. 
A life-sized language lab

They (the native speakers\} become the guinea pigs on which you try out your new words and constructions and they belp you if you make a mistake... For me being out of class and on the street became my laboratory for trying out what I learned in class. (Miller E Ginsberg, 1995: 307)

The study abroad participant who recorded the above impressions in his diary during his stay in Russia described the immersion environment as many students imagine it will be-a life-sized language laboratory full of native-speaking "assistants" whose help is freely given to those who make the effort to ask for it. Both Molise and Ashley seemed to share this expectation prior to their departure. As Molise put it, "I can't wait to use my French-not in a classroom!"

For Molise, the language-lab image was confirmed in actual experience, particularly within her host family situation, as she recounted in a retrospective interview:

The greatest opportunity (to use my French) was actually with my host family. I got to speak French every day with them and they even gave me feedback as far as my improvement.... They wouldn't be like on me like a hawk, but like if I made like some grave error, they'd just correct me, and if I like made little mistakes here and there, they wouldn't like make like a big a deal out of correcting me. They'd just go "Oh, oh, it's this" and then, you know, conversation goes on.... By the end of the month they told me that I improved tremendously as far as my French speaking skills and stuff. So, uh, yeah, that was like a major part of my French-like learning French there.

Ashley's expectations for laboratory-like practice with native speakers, on the other hand, did not coincide at all with her experiences, particularly in her home-stay situation, as previously described. She characterized the feedback she received from her host with an example:

She never really said that much (to me), and every time she'd say something, and I'd say, "Comment?" (to ask for repetition), she would just say, you know, "Oh, never mind. It doesn't matter," and wouldn't 
repeat it. I mean, obviously she wanted me to speak French, and if I didn't understand it on the first time, you know, that was too bad.

Outside the home, as counterintuitive as it may seem, the targetlanguage community did not require target-language use for a surprising number of the students' transactions. At the Brioche Dorée, one informant successfully ordered a hot chocolate by simply pointing to the researcher's and uttering "même" ("same"). Another cashed her traveler's checks at the bank with "Je voudrais changer?" ("I'd like to change?"). Still another made a purchase in Monoprix without exchanging a single word with the cashier.

Those that tried to put their book-learned French to use were often confronted with unexpected deviations, as one informant recalled: "Take the café, as in French 1. I remember doing all those little [skits].... Everybody has a part, you know, and when you go in to order something, you expect that part to come back at you. And they don't say that." Just as the café waiter had apparently not read the students' textbook, a Monoprix sales associate also failed to cast herself in a benevolent "lab assistant" role when she refused to refund Ashley's purchase of a malfunctioning hair dryer: "I was so mad!" Ashley recalled. "I couldn't believe what I was able to say-I was coming up with sentences that I'd never put together before.... I told her 'the customer is always right.' And you know what she said? She said I was crazy!... French people are so obstinate!"

One might expect that such departures from expectation provide fertile ground for learning. After all, Ashley was challenged to use her language skills in new ways to express ideas she had never before needed to phrase in French. She also witnessed evidence of a cultural difference between French and American standards for customer and salesperson roles: according to Carroll (1988), in France, unlike in America, "the employee holds a certain power over the client" (89), such that the customer is "at the mercy" of the clerk for service and information (90). Yet Ashley, like the others in the Collegiate group, did not tend to view such encounters in terms of learning opportunities. Instead, "the [FrenchAmerican] cultural difference being neither obvious nor even conceivable" (Carroll, 1988: 39), she could "only draw one of two conclusions: 'the French hate Americans,' or 'the French are cold (hostile/unpleasant/arrogant/despicable)' " (Carroll, 1988: 30). 
Laubscher (1994), in his investigation of study abroad participants' retrospective accounts of their out-of-class experiences, notes that in order for immersion to result in an increased understanding of the host culture, students need some sort of "decisive intervention," usually on the part of a "key [native-speaking] informant" to help them make sense of their encounters. "Simply having the data available," he observes, "is no assurance that substantive learning will take place" (106). In the absence of an insider perspective, participants "tend to interpret new experience in the light of past experience" (Laubscher, 1994: 107), just as Ashley did. It should be noted, however, that even when sojourners are fully aware of cultural differences, it is not uncommon for them to make a conscious decision not to conform to host-culture conventions in order to maintain their sense of self-identity (Giles, 1973; Siegal, 1995; Wieland, 1990). In short, the immersion context, far from the protected environment of a language lab, is a complex, multidimensional setting where verbal communication holds significant, yet often invisible, cultural and social meanings, in addition to the literal denotations which students are already trained in the classroom to recognize.

In the face of this unexpected deviation from pre-departure expectations, Molise and Ashley reacted quite differently. Molise relied on her altruistic hosts for advice and explanations; Ashley turned to three of her Collegiate peers for support. Molise's strategy deepened her immersion into French language and culture; Ashley's solution insulated her from her French surroundings in an American enclave where familiar activities, such as speaking English, sunbathing, drinking beer, and ordering homedelivery pizza, provided a sense of security and acceptance.

Looking back on the experience, Molise was struck by the contrast between her "before" and "after" perspectives on learning French:

(Before leaving for France) I didn't realize fully the fact that I did have to speak French-you know, use my French skills-especially with my host family, as well as communicating with my professors and stuff. I mean, I guess when it comes down to it, I just didn't believe that I could actually speak it, you know? It's kinda weird ... you're learning French in America, and your teachers are basically Americans, and the students, your classmates, are American, so you don't really get the sense that you're like actually knowing French. 
It's sort of like it's a course-it's there; you take it; you sort of learn. But basically you don't feel the practicality of it until you're actually there (in France), and you speak it.

Ashley, on the other hand, was surprised at how little difference she experienced between home and immersion contexts:

I was just so surprised that you could be in France for a month and ... really not speak French that often.... I mean, I probably spoke about maybe three sentences a day in French with my family, you know, "I'm leaving. I'll be home later," or during dinner, "Pass the so and so." I never really spoke.

Ultimately, Molise's experiences prompted her to change her major at Collegiate from biology to French and to return to France for an academic year of study. Ashley decided to shorten her stay in Valcourt from eight weeks to four and considered dropping her French minor. How are we then to understand such radically divergent perceptions of and reactions to the immersion context?

\section{Interpretations and Conclusions}

Although it may be tempting to point to one factor as the "cause" of Molise and Ashley's differences-perhaps the nature of their host families or a contrasting personality trait or an alternative approach to predeparture orientation-careful consideration of the data does not allow for a singular explanation. Clearly, their home-stay situations did play an important role in shaping their views of the French-speaking community. But other factors, such as their level of language proficiency, the nature of the pre-departure preparation meetings, the absence of an on-site director, their own cross-cultural experiences prior to their stay in France, and so forth, all had an impact as well.

In fact, some of the most influential factors may have been some of the least apparent on the surface. Bennett's (1986) Model of Intercultural Sensitivity suggests that people react in various ways to the "threatening idea" of "fundamental cultural difference," such as that encountered in most immersion contexts, depending on their own sensitivity to cultural diversity (28). He proposes a six-stage developmental continuum in 
which a person must pass through the three "ethnocentric states" of denial, defense, and minimization before reaching the "ethnorelative states" of acceptance, adaptation, and finally, integration (32). Applying this model to Molise and Ashley, it would seem that, despite their exposure to a variety of cultures from an early age, they were in different states on Bennett's scale. When faced with cultural difference in Valcourt, Ashley reacted defensively through denigration (e.g., "French people are so obstinate!") and "erection of ... social barriers to create distance from cultural difference" (e.g., the formation of an American clique) (Bennett, 1986: 35). Molise, on the other hand, seemed to be already at the ethnorelativist end of the spectrum before she left the United States. In an initial interview, she characterized the Cambodian-American lifestyle of her uprooted family as "some sort of strange mixture," making it seemingly impossible for her to be truly ethnocentric. As an ethnorelativist, her reactions to cultural differences would naturally be different from Ashley's, which apparently derived from an ethnocentric viewpoint.

Related to the issue of intercultural sensitivity is also the extent to which one feels threatened as a cultural and linguistic outsider in the host community. Speech Accommodation Theory (Giles, 1973; Giles \& Byrne, 1982) predicts that target-language contact within the immersion setting and language learning in general are a function of a person's perceptions of the host culture in relation to those of his or her home culture. In particular, if identification with one's own ethnic group is weak and one's first language is not important to that identity, then contact and increased proficiency are more likely to occur. Likewise, if beliefs, values, and attitudes between native and target-language communities are perceived to be similar, then the resulting attraction is more likely to precipitate communication within the immersion context and a desire to accommodate one's speech and behaviors to host-culture norms. Again, Molise's hybrid identity would seem to weaken her ties to one particular ethnic group, making it less threatening for her to try on a new identity as a foreigner in France. Moreover, her immersion experiences tended to emphasize for her the similarities between her beliefs and values and those of the French people whom she met. In contrast, Ashley's encounters with difference led her to seek similarity and identity confirmation among her American peers and eventually to avoid contact in the French community (to the point of planning to stop her study of the language). 
The role of American undergraduate group dynamics in influencing students' contacts within the host community is also documented in Kline's (1993) investigation of a junior-year abroad program in France. Most participants in her study seemed to use home-culture "anchors" to steady themselves as they faced their foreign surroundings: they all kept up with their college's newspaper, for example, and many established small clique-like clubs based on shared reading interests. Group influence on the immersion experience is illustrated in one reading club's reluctance to include native French speakers in its activities, despite the desire of certain individual members to invite their French friends to join. On the other hand, the group was the impetus for conversations with host family members about appropriate popular novels and other pleasure-reading materials. It is clearly impossible to anticipate and generalize all of the different ways that the compatriot community might impact participants' choices regarding immersion.

Like intragroup relations, issues of identity also surface in other studies of American sojourners overseas. Siegal (1995) and Wieland (1990) both describe informants who reported having made a conscious decision not to accommodate known sociolinguistic norms of the host community because to do so would have "compromised their own identity" (Wieland, 1990: 214). As Pellegrino (1997) notes, the extent to which one's identity seems threatened may vary from situation to situation, such that even the same learner may react differently depending on his perceptions of status and competence, his interlocutor's feedback, and his past experiences, among other factors.

Clearly, the immersion environment is more complex than any inventory of student behaviors can begin to describe. In answer to the questions posed at the beginning of this paper, even when the types of contacts available to students seem similar, perceptions of in-country encounters vary widely. In contrast to the messages commonly found in study-abroad recruitment literature that the host country is a homogeneous environment which mass-produces "fluent" speakers, the nature of the immersion context is, in actual experience, highly personal. Why one student dives into the host community head-first and another retreats to the shore after testing the waters hinges on the logical influences of a myriad of factors and circumstances, some of which may not be readily apparent. While it is certainly beneficial to consider generalized trends in attempting to under- 
stand the nature of immersion, to do so exclusively is to overlook that which defines this context for each unique participant. And ultimately, it is at the individual level that the impact of the experience is most intense, and its ramifications most influential and long-lasting.

\section{Notes}

1 Pseudonyms have been used for places, institutions, and people to protect anonymity. Institutional publications are not referenced in the bibliography for the same reason.

2 Space constraints here do not permit a detailed account of the study's design. Interested readers are referred to Wilkinson (1995) and Wilkinson (1998) for a more complete description of the project and its findings.

\section{References}

Bennett, M. J. 1986. Towards ethnorelativism: A developmental model of intercultural sensitivity. Cross-cultural orientation: New conceptualizations and orientations ed. R. M. Paige, pp. 27-69. Lanham, MD: University Press of America.

Brecht, R. D., D. Davidson, \& R. Ginsberg. 1993. Predictors of foreign language gain during study abroad. NFLC Occasional Paper. Washington, DC: National Foreign Language Center.

Brecht, R. D., \& J. Robinson. 1993. Qualitative analysis of second language acquisition in study abroad: The ACTR/NFLC project. NFLC Occasional Paper. Washington, DC: National Foreign Language Center.

Carlson, J. S., B. B. Burn, J. Useem, \& D. Yachimowicz. 1990. Study abroad: The experience of American undergraduates. Westport, CT: Greenwood Press.

Carroll, R. 1988. Cultural misunderstandings: The French-American experience trans. by C. Volk. Chicago: Chicago University Press.

De Ley, H. 1975. Organized programs of study in France: Some contributions of Stranger Theory. The French Review 48 (5): 836-847.

DeKeyser, R. M. 1991. Foreign language development during a semes- 
ter abroad. Foreign language acquisition research and the classroom ed. B. F. Freed, 104-119. Lexington, MA: D. C. Heath.

Freed, B. F. 1990. Language learning in a study abroad context: The effects of interaction and noninteractive out-of-class contact on grammatical achievement and oral proficiency. Linguistics, language teaching, and language acquisition: The interdependence of theory, practice, and research ed. J. E. Alatis, 459-477. Washington, DC: Georgetown University Press.

Freed, B. F. 1995a. Language learning and study abroad. Second Language Acquisition in a Study Abroad Context ed. B. F. Freed, 3-33. Amsterdam and Philadephia: John Benjamins.

Freed, B. F. 1995b. What makes us think that students who study abroad become fluent? Second Language Acquisition in a Study Abroad Context ed. B. F. Freed, 123-148. Amsterdam and Philadephia: John Benjamins.

Giles, H. 1973. Accent mobility: A model and some data. Antbropological Linguistics 15 (2): 87-105.

Giles, H., \& J. L. Byrne. 1982. An intergroup approach to second language acquisition. Journal of Multicultural and Multilingual Development 3: $17-40$.

Goodwin, C. D., \& M. Nacht. 1988. Abroad and beyond: Patterns in American overseas education. Cambridge: Cambridge University Press.

Kaplan, M. A. 1989. French in the community: A survey of language use abroad. The French Review 63 (2): 290-301.

Kline, R. R. 1993. The social practice of literacy in a program of study abroad. Ph.D. dissertation. The Pennsylvania State University, University Park.

Lafford, B. A. 1995. Getting into, through, and out of a survival situation: A comparison of communicative strategies used by students studying Spanish. Second Language Acquisition in a Study Abroad Context ed. B. F. Freed, 97-121. Amsterdam and Philadephia: John Benjamins.

Laubscher, M. L. 1994. Encounters with difference: Student perceptions of the role of out-of-class experiences in education abroad. Westport, CT: Greenwood Press. 
Miller, L., \& R. Ginsberg. 1995. Folklinguistic theories of language learning. Second Language Acquisition in a Study Abroad Context ed. B. F. Freed, 293-315. Amsterdam and Philadephia: John Benjamins.

Milleret, M. 1991. Assessing the gain in oral proficiency from summer foreign study. ADFL Bulletin 22 (3): 39-43.

Pellegrino, V. A. 1997. Speaking abroad: How interpersonal relations affect American students' use of Russian beyond the classroom. Paper presented at the annual meeting of the Modern Language Association, Toronto, Canada.

Polanyi, L. 1995. Language learning and living abroad: Stories from the field. Second Language Acquisition in a Study Abroad Context ed. B. F. Freed, 271-291. Amsterdam and Philadephia: John Benjamins.

Siegal, M. 1995. Individual differences and study abroad: Women learning Japanese in Japan. Second Language Acquisition in a Study Abroad Context ed. B. F. Freed, 225-244. Amsterdam and Philadephia: John Benjamins.

Spradley, J. P. 1979. The ethnographic interview. Philadelphia: Harcourt Brace.

Spradley, J. P. 1980. Participant observation. New York: Holt, Rinehart \& Winston.

Twombly, S. B. 1995. Piropos and friendships: Gender and culture clash in study abroad. Frontiers: The Interdisciplinary Journal of Study Abroad 1 (1): $1-27$.

Wieland, M. 1990. Politeness-based misunderstandings in conversations between native speakers of French and American advanced learners of French. Ph.D. dissertation. Indiana University, Bloomington.

Wilkinson, S. 1995. Foreign language conversation and the study abroad transition: A case study. Ph.D. dissertation. The Pennsylvania State University, University Park.

Wilkinson, S. 1998. Study abroad from the participants' perspective: A challenge to common beliefs. Foreign Language Annals 31 (1): 23-39. 